\title{
FAKTOR KEPERCAYAAN, GETOK TULAR, KUALITAS YANG DIPERSEPSI, KESADARAN MEREK SISWA SMA JAKARTA TERHADAP UNIVERSITAS XXX
}

\author{
Rudy Santosa Sudirga \\ Manajemen, Universitas Bunda Mulia, Jakarta. \\ Alamat surel: rudysudirga@yahoo.com
}

\begin{abstract}
Evaluation factors which include trust, word of mouth, perceived quality, and brand awareness are important in determining senior high school students' choice to study at University XXX. The research aims at identifing factors that are most important and interesting for the senior high school students in making their choice. A stratified random sampling of 400 senior high school students were employed to evaluate the evaluation of factors. In addition this sudy also aims to determine why senior high school students are interested in choosing University XXX. The Long term goal of this study is to determine whether changes need to be made and alterations have to be decided both in policy regarding the effectiveness of academic factors or other factors. In addition it will also look at the effectiveness measures of the academic promotion factor. For the marketing of University XXX, this research contributes in determining the strategy and other relevant factors to recruit more senior high school students to join University XXX.
\end{abstract}

Keywords: Trust, Word of Mouth, Perceived Quality

\section{Pendahuluan}

Latar Belakang

Seiring dengan meningkatnya persaingan universitas dan perguruan tinggi di Indonesia, maka semakin diperlukan pemahaman mengenai universitas yang akan dipilih oleh para siswa sekolah menengah atas setelah lulus. Realitas yang dihadapi adalah banyaknya pilihan universitas di dalam negeri dan di luar negeri yang merupakan pilihan tujuan siswa sekolah menengah atas memilih universitas. Penelitian terdahulu oleh Kang, Hustvedt (2013) menjelaskan bahwa getok tular dan kesadaran merek adalah faktor yang mempengaruhi purchase intention (niat beli), sedangkan penelitian oleh Sumaedi, Rakhmawati, Widianti, Yarmen (2014) menjelaskan bahwa kepercayaan dan kualitas yang dipersepsi adalah faktor yang utama di dalam memilih suatu jasa yang bertujuan untuk mencapai kepuasan.

\section{Masalah Penelitian}

Masalah yang dihadapi adalah mengevaluasi apa yang tertanam di pikiran para siswa sekolah menengah atas mengenai paradigma Universitas XXX. Faktor-faktor kepercayaan, getok tular, kualitas yang dipersepsi dan kesadaran merek merupakan peubah dari suatu produk atau jasa yang dapat menjelaskan mengenai seberapa besarkah nilai suatu produk atau jasa di suatu pasar, bagaimana tingkatannya bila dibandingkan dengan para pesaingnya, bagaimana kecenderungannya (trend) saat ini, apakah hal tersebut selalu dipertimbangkan, dan hal-hal apa saja yang dapat dilakukan untuk meningkatkan faktorfaktor tersebut yang merupakan tujuan penelitian.

\section{Tujuan Penelitian}

Tujuan penelitian ini untuk mengetahui faktor-faktor yang sebenarnya tertanam di ingatan konsumen para siswa sekolah menengah atas yang setelah lulus akan memilih universitas sebagai tujuan dan tempat belajar lanjutan bagi para siswa sekolah menengah atas tersebut. Selain itu dalam jangka panjang juga sangat berguna bagi Universitas XXX untuk merencanakan faktor-faktor apa saja, baik dalam bidang akademik serta pelayanan yang harus diterapkan oleh Universitas XXX agar dapat menjaring lebih banyak para siswa sekolah menengah atas menjadi calon mahasiswa di Universitas XXX. 


\section{Tinjauan Pustaka \\ Rerangka Pemikiran}

Penelitian ini terinspirasi dari penelitianpenelitian di jurnal internasional yang menyimpulkan bahwa faktor-faktor kepercayaan, getok tular, kualitas yang dipersepsi, dan kesadaran merek akan memengaruhi pengambilan keputusan untuk menentukan pilihan suatu produk atau jasa. Beberapa definisi konseptual adalah sebagai berikut:

- Telah dijelaskan bahwa kepercayaan dan kualitas yang dipersepsi adalah faktor yang utama di dalam memilih suatu jasa yang bertujuan untuk mencapai kepuasan.

Menurut Erdem and Swait (2004:191), trust is belief that someone or something is reliables, good, honest, and effective.

Menurut Keller, K.L. (2013:187), perceived quality can be defined as the customer's perception of the overall quality or superiority of a product or service with respect to its intended purpose.

- Telah dijelaskan pula bahwa getok tular dan kesadaran merek adalah faktor yang mempengaruhi purchase intention (niat beli).

Menurut Maxham and Netemeyer (2003:46), word of mouth is when a consumer's interest for a company's product or service is reflected in their daily dialogs.

Menurut Menurut Keller, K.L. (2013:73), brand awareness is the likelihood that consumers recognize the existence and availability of $a$ company's product or service.

Menurut Aaker (2007:679-680), brand awareness termasuk salah satu dari ekuitas merek, yaitu hal yang paling penting yang dipunyai suatu produk atau jasa, atau disebut nilai produk atau jasa. Aset dari ekuitas merek (brand equity) harus berhubungan dengan nama atau simbol dari brand (merek). Ekuitas merek ini berbeda dari satu konteks ke konteks yang lain dan dari produk atau jasa ke produk dan jasa lainnya.
Bagaimanapun juga, ekuitas merek ini dapat dibagi menjadi lima kategori, yaitu brand awareness, brand loyalty, perceived quality, brand association yang merupakan tambahan dari perceived quality, dan other brand assets, seperti patents, trademarks, channel relationships, dan lain-lain.

Dari ke lima kategori itu, salah satu yang terpenting adalah kesadaran merek (brand awareness), yang merupakan dimensi dari suatu produk atau jasa yang dapat menjelaskan mengenai seberapa besarkah nilai suatu kesadaran merek di suatu pasar, bagaimana tingkat kesadaran merek suatu produk atau jasa bila dibandingkan dengan para pesaingnya, bagaimana kecenderungan (trend) saat ini, apakah merek tersebut selalu dipertimbangkan, apakah kesadaran merek merupakan suatu masalah, dan hal-hal apa saja yang dapat dilakukan untuk meningkatkan kesadaran merek.

Menurut Hair, Black, Babin, Anderson, (2010:94-99), analisis faktor termasuk variasi seperti analisis komponen dan analisis faktor umum adalah pendekatan statistik yang dapat digunakan untuk menganalisis hubungan di antara beberapa peubah dan menjelaskan peubah-peubah ini dalam keadaan umumnya berdasarkan dimensi (faktor). Tujuannya adalah untuk mencari cara menyingkat informasi yang terdapat dalam beberapa peubah asal menjadi serangkaian peubah yang lebih kecil (faktor) dengan meminimalkan kehilangan informasi.

Dalam analisis faktor, dikenal dua pendekatan utama, yaitu analisis faktor eksploratoris dan analisis faktor konfirmatoris. Penelitian ini menggunakan analisis faktor eksploratoris bila banyaknya faktor yang akan terbentuk tidak ditentukan terlebih dahulu. Sebaliknya analisis faktor konfirmatoris digunakan apabila faktor yang terbentuk telah ditetapkan terlebih dahulu. Penelitian ini menggunakan analisis faktor eksploratoris.

Asumsi mendasar yang harus ditekankan dalam analisis faktor adalah bahwa peubahpeubah yang dianalisis memiliki keterkaitan 
atau saling berhubungan karena analisis faktor berusaha untuk mencari kesamaan dimensi (common dimension) yang mendasari peubah-peubah itu.

\section{Metode Penelitian}

Rancangan Penelitian

Dalam hal ini penelitian akan didisain dengan pertanyaan-pertanyaan kuesioner yang sesuai dengan indikator kunci untuk semua peubah yang sesuai dengan apa yang

Tabel 1. Daftar Sekolah Menengah Atas telah dijelaskan penulis di tinjauan pustaka untuk penelitian ini.

Dalam melakukan pengumpulan data penelitian, penulis menyebarkan kuesioner kepada para siswa sekolah menengah atas, keterbatasan waktu dan dana penelitian mengharuskan penulis membatasi pengumpulan data penelitian dari para siswa sekolah menengah atas dengan melakukan penyebaran kuesioner ke sekolah menengah atas yang ada di Jakarta Utara, Jakarta Timur, Jakarta Barat, dan Jakarta Pusat.

\begin{tabular}{|c|c|c|c|c|}
\hline SMA & Jakarta Utara & Jakarta Timur & Jakarta Barat & Jakarta Pusat \\
\hline Jacobus & $\sqrt{ }$ & & & \\
\hline Don Bosco 1 & $\sqrt{ }$ & & & \\
\hline Don Bosco 2 & $\sqrt{ }$ & & & \\
\hline Tarakanita & & $\sqrt{ }$ & & \\
\hline Penabur & $\sqrt{ }$ & & & \\
\hline Penabur Internasional & $\sqrt{ }$ & & & \\
\hline Penabur Pintu Air & & & $\sqrt{ }$ & \\
\hline Mahatma Gading & $\sqrt{ }$ & & & \\
\hline Universal School Kemayoran & & & & $\sqrt{ }$ \\
\hline St. Peter & $\sqrt{ }$ & & & \\
\hline Tunas Karya & $\sqrt{ }$ & & & \\
\hline Negeri 21 Pulomas & $\sqrt{ }$ & & & \\
\hline Fransiskus & & $\sqrt{ }$ & & \\
\hline Tugasku & $\sqrt{ }$ & & & \\
\hline Sevilla School & $\sqrt{ }$ & & & \\
\hline Dharma Budhi Bakti & $\sqrt{ }$ & & & \\
\hline XXX Sangaji & & & $\sqrt{ }$ & \\
\hline Budi Mulia & & & $\sqrt{ }$ & \\
\hline Bhineka Tunggal Ika & & & $\sqrt{ }$ & \\
\hline Mangga Besar & & & $\sqrt{ }$ & \\
\hline Pelita 2 & & & $\sqrt{ }$ & \\
\hline Santo Kristoferus 2 & & & $\sqrt{ }$ & \\
\hline Santo Leo 1 & & & $\sqrt{ }$ & \\
\hline SMAK 1 BPK Penabur & & & $\sqrt{ }$ & \\
\hline SMAK 2 BPK Penabur & & & $\sqrt{ }$ & \\
\hline Kanisius & & & & $\sqrt{ }$ \\
\hline Santa Theresia & & & & $\sqrt{ }$ \\
\hline Santa Ursula & & & & \\
\hline SMAK Ketapang & & & $\sqrt{ }$ & \\
\hline Harapan Jaya & & & $\sqrt{ }$ & \\
\hline Cengkareng 1 & & & $\sqrt{ }$ & \\
\hline Tarsisius 1 & & & $\sqrt{ }$ & \\
\hline Al Azhar & $\sqrt{ }$ & & & \\
\hline
\end{tabular}


Penelitian ini menggunakan skala Likert 5 poin, dan jenis penelitian ini adalah penelitian eksploratif.

Menurut Zikmund, Babin (2007:318), Likert scale is a measure of attitudes and attitude is usually measured with an interval scale. An attitude of zero means nothing. Peubah-peubah yang terpenting dalam penelitian ini ditentukan oleh indikatorindikator sebagai berikut:

Tabel 2. Indikator Peubah

\begin{tabular}{|c|c|c|}
\hline Peubah & ndikator & Rujukan \\
\hline $\begin{array}{l}\text { - Trust (Kepercayaan) } \\
\text { Trust is belief that someone } \\
\text { or something is reliables, } \\
\text { good, honest, and effective, } \\
(\text { Erdem and Swait, } \\
2004: 191) .\end{array}$ & $\begin{array}{l}\text { - people believe that something is true; } \\
\text { - brand's product claims are believeable; } \\
\text { - overtime my experiences with this brand have } \\
\text { led me to expect it to keep its promises; } \\
\text { - brand has a name you can trust; } \\
\text { - brand delivers what it promises; } \\
\text { - the integrity of the company; } \\
\text { - the company has skill and ability to perform the } \\
\text { promised; } \\
\text { - the company will strive to satisfy the customer. }\end{array}$ & $\begin{array}{l}\text { Erdem and Swait } \\
(2004: 191-198)\end{array}$ \\
\hline $\begin{array}{l}\text { - Word of Mouth (Getok } \\
\text { tular) } \\
\text { Word of mouth is when a } \\
\text { consumer's interest for a } \\
\text { company's product or } \\
\text { service is reflected in their } \\
\text { daily dialogs, (Maxham and } \\
\text { Netemeyer, 2003:46). }\end{array}$ & $\begin{array}{l}\text { - I'm likely to spend positive word of mouth } \\
\text { about this brand; } \\
\text { - I would reccommend this brand to my firend; } \\
\text { - if my friends were looking to get something, I } \\
\text { would tell them to try this brand; } \\
\text { - the condition that somebody have trusted to this } \\
\text { brand. }\end{array}$ & $\begin{array}{l}\text { Maxham and } \\
\text { Netemeyer } \\
(2003: 46-62)\end{array}$ \\
\hline $\begin{array}{l}\text { - Perceived Quality (Kualitas } \\
\text { yang dipersepsi) } \\
\text { Perceived quality can be } \\
\text { defined as the customer's } \\
\text { perception of the overall } \\
\text { quality or superiority of a } \\
\text { product or service with } \\
\text { respect to its intended } \\
\text { purpose, (Keller, K.L. } \\
\text { 2013:187). }\end{array}$ & $\begin{array}{l}\text { - customers' perception of the overall quality or } \\
\text { superiority of a product or service compared to } \\
\text { alternatives and with respect to its intended } \\
\text { purpose; } \\
\text { - primary ingredients and supplementary } \\
\text { features; } \\
\text { - product reliability; durability and serviceability; } \\
\text { - style and design. } \\
\text { - decision rules based on brand reputation or } \\
\text { product characteristics. }\end{array}$ & $\begin{array}{l}\text { Keller, } \\
(2013: 187)\end{array}$ \\
\hline $\begin{array}{l}\text { - Brand awareness } \\
\text { (Kesadaran merek) } \\
\text { Brand awareness is the } \\
\text { likelihood that consumers } \\
\text { recognize the existence and } \\
\text { availability of a company's } \\
\text { product or service, (Keller, } \\
\text { K.L. 2013:73), }\end{array}$ & $\begin{array}{l}\text { - brand recognition is consumer's ability to } \\
\text { confirm prior exposure to the brand when given } \\
\text { the brand as a cue; } \\
\text { - brand recall is consumer's ability to retrieve the } \\
\text { brand from memory when given the product } \\
\text { category; } \\
\text { - learning advantages; } \\
\text { - consideration advantages; } \\
\text { - choice advantages. }\end{array}$ & $\begin{array}{l}\text { Keller, } \\
(2013: 73-74)\end{array}$ \\
\hline
\end{tabular}

Populasi dan Sampel

Menurut Husein Umar (2003:141-142), untuk menentukan berapa minimal sampel yang dibutuhkan jika ukuran populasi diketahui, dapat digunakan rumus Slovin.
Di dalam penelitian ini, yang dijadikan populasi adalah siswa SMA di Jakarta. Jumlah siswa SMA negeri di Jakarta adalah 92734, sedangkan jumlah siswa SMA swasta di Jakarta adalah 90532, sehingga 
keseluruhan jumlah siswa SMA di Jakarta adalah 183266 orang. Maka jumlah sampel yang dibutuhkan untuk penelitian ini adalah $\mathrm{n}=399.13$ atau dibulatkan menjadi 400 sampel penelitian.

\section{Pengumpulan Data}

Cara pengambilan sampel yang dilakukan penulis adalah dengan memakai 2 (dua) orang mahasiswa program studi manajemen Universitas XXX, dan ke dua siswa tersebut dipilih penulis untuk menyebarkan kuesioner kepada para siswa sekolah menengah atas di Jakarta. Teknik pengambilan sampel yang dilakukan oleh penulis adalah dengan proportionate stratified random sampling (sampling bertingkat proporsional) yang termasuk probability sampling atau random sampling.

\section{Analisis Data}

Prinsip utama dalam analisis faktor adalah korelasi, artinya peubah yang memiliki korelasi erat akan membentuk suatu faktor, sedangkan peubah yang ada dalam suatu faktor akan memiliki korelasi yang lemah dengan peubah yang terdapat pada faktor yang lain. Karena prinsip utama analisis faktor adalah korelasi, maka asumsi dalam analisis faktor berkaitan erat dengan korelasi berikut :

1. Nilai KMO yang kecil menunjukkan bahwa analisis faktor bukan merupakan pilihan yang tepat. Untuk dapat dilakukan faktor analisis, nilai KMO dianggap cukup apabila nilai $\mathrm{KMO} \geq$ 0.5

2. Untuk dapat dilakukan analisis faktor, nilai MSA dianggap cukup apabila nilai $\mathrm{MSA} \geq 0.5$. Apabila ada item/peubah yang tidak memiliki nilai MSA $\geq 0.5$, variabel tersebut harus dikeluarkan dari analisis faktor secara bertahap satu per satu.

3. Dalam beberapa kasus, setiap peubah yang akan dianalisis dengan menggunakan analisis faktor harus menyebar secara normal.

Tabel KMO dan Bartlett's Test menunjukkan uji kelayakan dari analisis faktor. Menurut Hair, Black, Babin, Anderson (2010), nilai KMO MSA (KaiserMeyer-Olkin Measure of Sampling Adequacy) harus lebih besar dari 0.5 (KMO MSA > 0.5) dan nilai Sig (Significance Level) harus < 0.05, agar penelitian dapat dilanjutkan untuk proses analisis faktor.

Tabel 3. Tabel Ukuran Ketepatan

Kaiser-Meyer-Olkin, Measure of Sampling Adequacy

\begin{tabular}{|l|l|}
\hline KMO Index & Classification \\
\hline$>0.9$ & Marvelous \\
$0.8-0.9$ & Meritorious \\
$0.7-0.8$ & Milding \\
$0.6-0.7$ & Mediacore \\
$0.5-0.6$ & Miserable \\
$<0.5$ & Unacceptable \\
\hline
\end{tabular}

Sumber: Hair, Black, Babin, Anderson, Multivariate Data Analysis, 7th edition, 2010

Secara umum, analisis faktor dapat dilakukan bila indeks KMO lebih besar dari 0.5. Bartlett's test digunakan untuk menguji apakah matriks korelasi hubungan antara peubah adalah matriks identitas. Hal ini digunakan untuk menguji kecukupan hubungan antara peubah dimana matriks identitas berisikan diagonal matriks dengan nilai Eigenvalue > 1. (Eigenvalue represents the total variance explained by each factor, jadi maksudnya Eigenvalue adalah angka atau nilai yang menunjukkan total variance dari tiap faktor yang dapat dijelaskan oleh faktor baru yang terbentuk)

Berdasarkan nilai indeks KMO dari hasil output SPSS, bila indeks KMO > 0.5, maka model faktor yang terbentuk layak digunakan. Setelah pemeriksaan terhadap 
nilai KMO dan Bartlett's test, dilakukan juga pemeriksaan terhadap nilai anti-image correlation yang ditunjukkan oleh nilai diagonal dari kiri atas ke kanan bawah yang bertanda huruf a pada setiap nilainya (nilai Measure of Sampling Adequacy, MSA).

Bila nilai MSA $<0.5$ maka peubah tersebut sebaiknya dibuang dari sistem analisis dan dilakukan analisis ulang hingga mencapai semua nilai MSA > 0.5 .
Bila semua nilai MSA $>0.5$ maka peneliti dapat melanjutkan dan melakukan analisis faktor dan analisis faktor dianggap cukup layak dan dapat dipercaya hasilnya.

Menurut Hair, Black, Babin, Anderson (2010:117), a factor loading of 0.30 significant only for sample sizes of 350 or greater.

Tabel 4. Guidelines for Identifying Significant Factor Loadings Based on Sample Size

\begin{tabular}{|l|l|}
\hline Factor Loading & Sample Size Needed for Significance \\
\hline 0.30 & 350 \\
\hline 0.35 & 250 \\
\hline 0.40 & 200 \\
\hline 0.45 & 150 \\
\hline 0.50 & 120 \\
\hline 0.55 & 100 \\
\hline 0.60 & 85 \\
\hline 0.65 & 70 \\
\hline 0.70 & 60 \\
\hline 0.75 & 50 \\
\hline
\end{tabular}

*Significance is based on 0.05 significance level $(\alpha)$

Dalam analisis kehandalan digunakan koefisien Alpha Cronbach, yang merupakan koefisien kehandalan yang paling sering digunakan. Pertanyaan yang handal harus memiliki nilai Alpha Cronbach lebih besar dari 0.6 (Malhotra, 2010:319) atau 0.7 (Uyanto, S.S., 2009:274), agar supaya hasil diatas dianggap handal, dapat digunakan dan mempunyai kehandalan yang baik. Alpha Cronbach dapat diinterpretasikan sebagai korelasi dari skala yang diamati (observed scale) dengan semua kemungkinan pengukuran skala lain yang mengukur hal yang sama dan menggunakan jumlah butir pertanyaan yang sama.

Menurut Nisfiannoor (2009:229-230), bila angka korelasi yang terdapat pada kolom Corrected Item-Total Correlation berada di bawah 0.2 atau bertanda negatif (-), maka dinyatakan tidak sahih (gugur). Sebaliknya bila angka korelasinya di atas 0.2, maka dinyatakan sahih. 


\section{Hasil}

Statistik Deskriptif Indikator Dari Peubah Kepercayaan, Getok Tular, Kualitas Yang Dipersepsi, dan Kesadaran Merek :

Tabel 5. Descriptive Statistics $(\mathrm{N}=400)$

\begin{tabular}{|c|c|c|c|c|c|c|}
\hline & $\mathrm{N}$ & Minimum & Maximum & Mean & Std. Deviation & Variance \\
\hline$q 1$ & 400 & 1 & 5 & 3.68 & .808 & .652 \\
\hline $\mathrm{q} 2$ & 400 & 1 & 5 & 3.74 & .841 & .708 \\
\hline q3 & 400 & 1 & 5 & 3.73 & .841 & .708 \\
\hline $\mathrm{q} 4$ & 400 & 1 & 5 & 3.78 & .863 & .745 \\
\hline q5 & 400 & 1 & 5 & 3.78 & .862 & .743 \\
\hline q6 & 400 & 1 & 5 & 3.73 & .841 & .708 \\
\hline q7 & 400 & 1 & 5 & 3.81 & .920 & .846 \\
\hline q8 & 400 & 1 & 5 & 3.79 & .868 & .754 \\
\hline q9 & 400 & 1 & 5 & 3.72 & .870 & .757 \\
\hline q10 & 400 & 1 & 5 & 3.80 & .910 & .829 \\
\hline q11 & 400 & 1 & 5 & 3.68 & .874 & .765 \\
\hline q12 & 400 & 1 & 5 & 3.72 & .887 & .786 \\
\hline q13 & 400 & 1 & 5 & 3.76 & .847 & .717 \\
\hline q14 & 400 & 1 & 5 & 3.71 & .787 & .620 \\
\hline$q 15$ & 400 & 1 & 5 & 3.69 & .842 & .709 \\
\hline q16 & 400 & 1 & 5 & 3.68 & .856 & .734 \\
\hline q17 & 400 & 1 & 5 & 3.81 & .908 & .824 \\
\hline q18 & 400 & 1 & 5 & 3.78 & .821 & .675 \\
\hline q19 & 400 & 1 & 5 & 3.76 & .818 & .669 \\
\hline$q 20$ & 400 & 1 & 5 & 3.83 & .906 & .821 \\
\hline Valid N (listwise) & 400 & & & & & \\
\hline
\end{tabular}

Sumber: Dari data primer

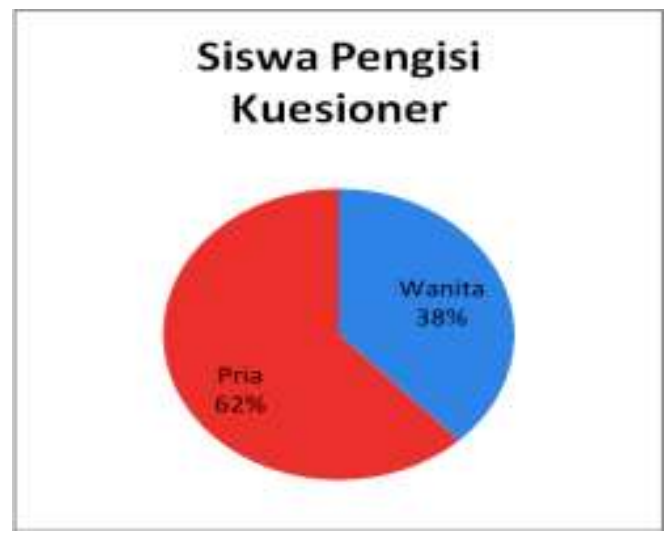

Gambar 1

Siswa Pengisi Kuesioner ( $\mathrm{N}=400)$

Pengisi kuesioner wanita 152 orang (38\%), dan pengisi kuesioner pria 248 orang (62\%). 


\section{Kesahihan dan Kehandalan}

Tabel 6. Reliability Statistics

\begin{tabular}{|c|c|}
\hline Cronbach's Alpha & N of Items \\
\hline .914 & 20 \\
\hline
\end{tabular}

Hasil tes kesahihan dan kehandalan didapatkan semua angka Corrected ItemTotal Correlation > 0.2, sehingga indikator dianggap sangat sahih, dan kehandalan Cronbach's Alpha sebesar $0.914>0.7$, yang berarti handal, sehingga penelitian dianggap sangat sahih dan handal untuk dilakukan proses pengolahan hasil penelitian. Penelitian faktor analisis dapat dilanjutkan dengan menganalisis semua 20 kuesioner, tanpa ada kuesioner yang harus dikeluarkan dari penelitian.

\section{Analisis Faktor}

Untuk menguji ketepatan dalam model faktor analisis, uji statistik yang digunakan adalah Bartletts Test Sphericity dan KaiserMeyer-Olkin Measure of Sampling Adequacy (KMO MSA).

Proses selanjutnya adalah melihat tabel anti-image matrics untuk menentukan peubah mana saja yang layak digunakan dalam analisis faktor lanjutan. Pada tabel tersebut ada kode "a" yang artinya tanda untuk Measure of Sampling Adequacy (MSA). Bila nilai MSA $<0.5$ maka peubah tersebut sebaiknya dibuang dari sistem analisis dan dilakukan analisis ulang hingga mencapai semua nilai MSA $>0.5$.
Hanya faktor yang memiliki nilai eigenvalue sama atau lebih besar dari 1 (eigenvalue $\geq 1$ ) yang dipertahankan dalam model analisis faktor, sedangkan yang lainnya dengan nilai eigenvalue $<1$ harus dikeluarkan dari model. Menurut Aaker, Kumar, and Day (2007: 567),"an eigenvalue represents the amount of variance in the original varables that is associated with a factor. Hence, only factors with eigenvalues greater than 1.0 are included."

Melalui rotasi analisis faktor, faktor matriks ditransformasikan ke dalam matriks yang lebih sederhana sehingga mudah untuk diinterpretasikan. Rotasi faktor ini umumnya menggunakan prosedur Varimax. Metode yang umum dan populer digunakan adalah Varimax Method, yaitu teknik rotasi orthogonal untuk meringkas beberapa peubah yang mempunyai tingkat loading factor yang tinggi dan berkontribusi kuat pada faktor yang terbentuk.

Interpretasi faktor dilakukan dengan mengklasifikasikan peubah yang mempunyai tingkat factor loading minimum 0.30, sedangkan variabel dengan factor loading < 0.30 harus dikeluarkan dari model.

Tabel 7. KMO and Bartlett's Test $(\mathrm{N}=400)$

\begin{tabular}{|ll|l|}
\hline \multicolumn{2}{|l|}{ Kaiser-Meyer-Olkin Measure of Sampling Adequacy. } & .939 \\
Bartlett's Test $\quad$ of Approx. Chi-Square & 2819.917 \\
Sphericity & Df & 190 \\
& Sig. & .000 \\
\hline
\end{tabular}

Dari tabel 7 dapat dilihat bahwa hasil SPSS menunjukkan KMO MSA sebesar 0.939 (menurut Hair, Black, Babin, Anderson, pada tabel 7 nilai KMO MSA > 0.9 adalah marvelous, atau excellent).

\section{Anti-image Matrices}

Pada hasil SPSS Anti-image Matrices (lihat lampiran output SPSS), pada bagian Anti-image Correlation terlihat bahwa semua angka-angka dari diagonal kiri atas ke diagonal kanan bawah yang bertanda "a" 
yang menandakan besarnya MSA sebuah peubah semuanya berada pada nilai $>0.5$ sehingga dapat disimpulkan bahwa semua peubah dapat dimasukkan dalam proses faktor analisis dan proses faktor analisis dapat dilanjutkan dan tidak ada peubah yang harus dikeluarkan dari analisis faktor.

Tabel 8. Total Variance Explained

\begin{tabular}{|c|c|c|c|c|c|c|c|c|c|}
\hline \multirow[b]{2}{*}{$\begin{array}{l}\text { Compo- } \\
\text { nent }\end{array}$} & \multicolumn{3}{|c|}{ Initial Eigenvalues } & \multicolumn{3}{|c|}{\begin{tabular}{|l|l|} 
Extraction Sums of \\
Squared Loadings
\end{tabular}} & \multicolumn{3}{|c|}{ Rotation Sums of Squared Loadings } \\
\hline & Total & $\begin{array}{lr}\% & \text { of } \\
\text { Variance }\end{array}$ & $\begin{array}{l}\text { Cumu- } \\
\text { lative } \\
\% \\
\end{array}$ & Total & \begin{tabular}{|l|}
$\%$ of \\
Varianc \\
$e$
\end{tabular} & $\begin{array}{l}\text { Cumu- } \\
\text { lative } \\
\%\end{array}$ & Total & $\begin{array}{l}\% \text { of } \\
\text { Variance }\end{array}$ & $\begin{array}{l}\text { Cumulative } \\
\%\end{array}$ \\
\hline 1 & 7.618 & 38.089 & 38.089 & 7.618 & 38.089 & 38.089 & 3.626 & \begin{tabular}{|l}
18.131 \\
\end{tabular} & 18.131 \\
\hline 2 & 1.262 & 6.310 & 44.399 & 1.262 & 6.310 & 44.399 & 3.216 & 16.081 & 34.212 \\
\hline 3 & 1.056 & 5.278 & 49.677 & 1.056 & 5.278 & 49.677 & 3.093 & 15.465 & 49.677 \\
\hline 4 & .876 & 4.379 & 54.055 & & & & & & \\
\hline 5 & .806 & 4.030 & 58.086 & & & & & & \\
\hline 6 & .786 & 3.929 & 62.015 & & & & & & \\
\hline 7 & .748 & 3.741 & 65.756 & & & & & & \\
\hline 8 & .713 & 3.567 & 69.323 & & & & & & \\
\hline 9 & .680 & 3.398 & 72.721 & & & & & & \\
\hline 10 & .655 & 3.275 & 75.996 & & & & & & \\
\hline 11 & .628 & 3.138 & 79.134 & & & & & & \\
\hline 12 & .559 & 2.797 & 81.931 & & & & & & \\
\hline 13 & .545 & 2.724 & 84.655 & & & & & & \\
\hline 14 & .513 & 2.564 & 87.219 & & & & & & \\
\hline 15 & .498 & 2.489 & 89.708 & & & & & & \\
\hline 16 & .476 & 2.379 & 92.087 & & & & & & \\
\hline 17 & .444 & 2.218 & 94.305 & & & & & & \\
\hline 18 & 419 & 2.095 & 96.399 & & & & & & \\
\hline 19 & .387 & 1.934 & 98.333 & & & & & & \\
\hline 20 & .333 & 1.667 & $\begin{array}{l}100.00 \\
0\end{array}$ & & & & & & \\
\hline
\end{tabular}

Extraction Method: Principal Component Analysis.

Tabel 8 Total Variance Explained, digunakan untuk mengetahui banyaknya faktor yang terbentuk. Faktor yang terbentuk harus mempunyai nilai eigenvalue $>1$. Dari hasil analisis dapat diperoleh informasi bahwa jumlah faktor yang terbentuk adalah 3 faktor, yaitu faktor pertama dengan nilai eigenvalue 7.618 , faktor kedua dengan nilai eigenvalue 1.262, dan faktor ketiga dengan nilai eigenvalue 1.056. Jumlah total dari semua eigenvalue adalah $7.618+1.262+$ $1.056+0.876+0.806+0.786+0.748+$ $0.713+0.680+0.655+0.628+0.559+$ $0.545+0.513+0.498+0.476+0.444+$
$0.419+0.387+0.333=20$ atau sama dengan jumlah peubah yang dianalisis, yaitu 20 peubah. Persentase varian dari faktor kesatu (1) yang terbentuk adalah (7.618/20) x $100 \%$ $=38.09 \%$, sedangkan persentase varian dari faktor kedua (2) yang terbentuk adalah $(1.262 / 20) \times 100 \%=6.31 \%$, sedangkan persentase varian dari faktor ketiga (3) yang terbentuk adalah (1.056/20) $\mathrm{x} 100 \%=$ $5.28 \%$, seperti yang ditunjukkan pada kolom Persentase Varian di tabel 8 Sehingga dapat disimpulkan bahwa persentase varian kumulatif ketiga faktor yang terbentuk adalah $38.09 \%+6.31 \%+5.28 \%=49.68 \%$. 


\begin{tabular}{|c|c|c|c|}
\hline & \multicolumn{3}{|c|}{ Component } \\
\hline & 1 & 2 & 3 \\
\hline Universitas XXX mempunyai nama yang baik dan benar & .610 & -.387 & -.144 \\
\hline Nama Universitas XXX dapat dipercaya & .648 & -.230 & -.313 \\
\hline Universitas XXX mempunyai integritas yang baik & .686 & -.175 & -.069 \\
\hline Universitas XXX memiliki skill dan kemampuan sesuai dengan yang diharapkan & .634 & -.070 & -.368 \\
\hline Universitas XXX akan berusaha untuk memuaskan para mahasiswanya yang bergabung & .665 & -.069 & -.212 \\
\hline $\begin{array}{l}\text { Saya akan menyebarkan dan memberitahukan hal yang positif mengenai Universitas } \\
\text { XXX }\end{array}$ & .631 & -.070 & -.234 \\
\hline Saya akan merekomendasikan Universitas XXX kepada teman teman saya & .619 & .116 & -.147 \\
\hline $\begin{array}{l}\text { Jika teman saya akan memilih universitas, saya akan memberitahukan teman saya untuk } \\
\text { memilih Universitas XXX }\end{array}$ & .622 & -.007 & -.233 \\
\hline Nama Universitas XXX sudah mencapai kondisi yang dapat dipercaya & .588 & .330 & -.080 \\
\hline Universitas XXX mempunyai konsistensi hal yang positif di masyarakat & .594 & .454 & .191 \\
\hline $\begin{array}{l}\text { Persepsi saya mengenai kualitas Universitas XXX adalah lebih baik secara keseluruhan } \\
\text { dibandingkan universitas lainnya yang setingkat }\end{array}$ & .610 & .274 & .036 \\
\hline Program studi di Universitas XXX sesuai dengan yang saya harapkan & .587 & .396 & -.069 \\
\hline Saya percaya Universitas XXX dapat melakukan pelayanan dengan baik & .618 & .433 & -.062 \\
\hline $\begin{array}{l}\text { Saya percaya Universitas XXX mempunyai style dan design mata pelajaran yang } \\
\text { bermutu dan baik }\end{array}$ & .622 & -.089 & .103 \\
\hline $\begin{array}{l}\text { Saya percaya Universitas XXX mempunyai reputasi dan karakteristik belajar dan } \\
\text { mengajar yang baik dan bermutu }\end{array}$ & .650 & -.050 & .241 \\
\hline Nama Universitas XXX sudah dikenal di Jakarta & .550 & .027 & .429 \\
\hline $\begin{array}{l}\text { Diantara nama universitas di Jakarta, nama Universitas XXX merupakan salah satu } \\
\text { nama yang dikenal oleh masyarakat }\end{array}$ & .601 & -.244 & .112 \\
\hline $\begin{array}{l}\text { Nama Universitas XXX dijadikan salah satu hal yang layak dipelajari dalam memilih } \\
\text { suatu universitas }\end{array}$ & .609 & -.221 & .375 \\
\hline $\begin{array}{l}\text { Nama Universitas XXX dijadikan salah satu pertimbangan dalam memilih suatu } \\
\text { universitas }\end{array}$ & .550 & -.382 & .210 \\
\hline $\begin{array}{l}\text { Nama Universitas XXX merupakan salah satu pilihan dalam menentukan kuliah di } \\
\text { universitas di Jakarta }\end{array}$ & .631 & .008 & .345 \\
\hline
\end{tabular}

Extraction Method: Principal Component Analysis.

a. 3 components extracted.

Tabel 9 Component Matrix digunakan untuk mendistribusikan peubah-peubah yang telah diekstrak ke dalam faktor yang terbentuk berdasarkan factor loading nya. Interpretasi faktor dilakukan dengan mengklasifikasikan peubah yang mempunyai tingkat factor loading minimum 0.30 sedangkan peubah dengan factor loading < 0.30 harus dikeluarkan dari model. Dari tabel 4 Guidelines for Identifying Significant Factor Loadings Based on Sample Size berdasarkan jumlah sampel penelitian yang diambil yaitu 400 responden, didapatkan factor loading sebesar 0.30. Peubah yang mempunyai tingkat factor loading di atas 0.30 adalah peubah yang dipilih oleh responden dengan nilai yang tinggi, maksudnya nilai dari para responden yang memilih nilai $4=$ setuju dan $5=$ sangat setuju, sedangkan nilai rendah yang dipilih oleh para responden akan memunculkan peubah dengan nilai factor loading di bawah 0.30. Berdasarkan hasil component matrix, misalkan pada peubah ke 10 yaitu "Universitas XXX mempunyai konsistensi hal yang positif di masyarakat" sebelum dilakukan Rotated Component Matrix akan masuk ke dalam faktor 1 (utama). Hal ini karena korelasi peubah "Universitas XXX mempunyai konsistensi hal yang positif di masyarakat" korelasi terhadap faktor 1 adalah sebesar 0.594 lebih besar daripada korelasi terhadap faktor 2 yang hanya sebesar 0.454 , dan juga lebih besar daripada korelasi faktor 3 yang hanya sebesar 0.191 . 


\begin{tabular}{|c|c|c|c|}
\hline & \multicolumn{3}{|c|}{ Component } \\
\hline & 1 & 2 & 3 \\
\hline Universitas XXX mempunyai nama yang baik dan benar & .635 & & .372 \\
\hline Nama Universitas XXX dapat dipercaya & .706 & & \\
\hline Universitas XXX mempunyai integritas yang baik & .545 & & .393 \\
\hline Universitas XXX memiliki skill dan kemampuan sesuai dengan yang diharapkan & .667 & & \\
\hline $\begin{array}{l}\text { Universitas XXX akan berusaha untuk memuaskan para mahasiswanya yang } \\
\text { bergabung }\end{array}$ & .582 & .311 & \\
\hline $\begin{array}{l}\text { Saya akan menyebarkan dan memberitahukan hal yang positif mengenai Universitas } \\
\text { XXX }\end{array}$ & .577 & & \\
\hline Saya akan merekomendasikan Universitas XXX kepada teman teman saya & .434 & .440 & \\
\hline $\begin{array}{l}\text { Jika teman saya akan memilih universitas, saya akan memberitahukan teman saya } \\
\text { untuk memilih Universitas XXX }\end{array}$ & .544 & .339 & \\
\hline Nama Universitas XXX sudah mencapai kondisi yang dapat dipercaya & & .601 & \\
\hline Universitas XXX mempunyai konsistensi hal yang positif di masyarakat & & .707 & .305 \\
\hline $\begin{array}{l}\text { Persepsi saya mengenai kualitas Universitas XXX adalah lebih baik secara } \\
\text { keseluruhan dibandingkan universitas lainnya yang setingkat }\end{array}$ & & .566 & \\
\hline Program studi di Universitas XXX sesuai dengan yang saya harapkan & & .655 & \\
\hline Saya percaya Universitas XXX dapat melakukan pelayanan dengan baik & & .703 & \\
\hline $\begin{array}{l}\text { Saya percaya Universitas XXX mempunyai style dan design mata pelajaran yang } \\
\text { bermutu dan baik }\end{array}$ & .355 & & .454 \\
\hline $\begin{array}{l}\text { Saya percaya Universitas XXX mempunyai reputasi dan karakteristik belajar dan } \\
\text { mengajar yang baik dan bermutu }\end{array}$ & & .318 & .558 \\
\hline Nama Universitas XXX sudah dikenal di Jakarta & & .327 & 615 \\
\hline $\begin{array}{l}\text { Diantara nama universitas di Jakarta, nama Universitas XXX merupakan salah satu } \\
\text { nama yang dikenal oleh masyarakat }\end{array}$ & .400 & & .506 \\
\hline $\begin{array}{l}\text { Nama Universitas XXX dijadikan salah satu hal yang layak dipelajari dalam memilih } \\
\text { suatu universitas }\end{array}$ & & & 699 \\
\hline $\begin{array}{l}\text { Nama Universitas } \mathrm{XXX} \text { dijadikan salah satu pertimbangan dalam memilih suatu } \\
\text { universitas }\end{array}$ & .361 & & 602 \\
\hline $\begin{array}{l}\text { Nama Universitas XXX merupakan salah satu pilihan dalam menentukan kuliah di } \\
\text { universitas di Jakarta }\end{array}$ & & .356 & 604 \\
\hline
\end{tabular}

Extraction Method: Principal Component Analysis.

Rotation Method: Varimax with Kaiser Normalization.

a. Rotation converged in 7 iterations.

Tabel 10 Rotated Component Matrix, menunjukkan nilai korelasi antara setiap peubah terhadap faktor yang terbentuk. Nilai korelasi ini disebut juga factor loading. Tanpa melihat tanda (+/-) pada nilai factor loading ke 20 variabel, maka ke 20 variabel dapat direduksi menjadi 3 faktor saja yaitu yang mempunyai nilai eigenvalue $\geq 1$. Pengelompokan tiap variabel untuk masuk dalam suatu faktor dilihat dari loading factor yang terbesar.

\section{Pembahasan}

Dengan demikian dapat disimpulkan bahwa faktor yang menentukan evaluasi faktor kepercayaan, penyebaran dari mulut ke mulut, persepsi kualitas, dan kesadaran merek para siswa sekolah menengah atas di Jakarta terhadap Universitas XXX dapat dikelompokkan hanya dalam 3 faktor saja, yang mencerminkan evaluasi para siswa sekolah menengah atas di Jakarta terhadap Universitas XXX.

Faktor 1 yang sangat mendukung evaluasi faktor kepercayaan, getok tular, persepsi kualitas, dan kesadaran merek para siswa sekolah menengah atas di Jakarta terhadap Universitas XXX, terdiri dari faktor:

- "Nama Universitas XXX dapat dipercaya", dengan nilai faktor tertinggi 0.706 , 
- "Universitas XXX memiliki skill dan kemampuan sesuai dengan yang diharapkan", dengan nilai faktor 0.667 ,

- "Universitas XXX mempunyai nama yang baik dan benar", dengan nilai faktor 0.635 ,

- "Universitas XXX akan berusaha untuk memuaskan para mahasiswanya yang bergabung", dengan nilai faktor 0.582 ,

- "Saya akan menyebarkan dan memberitahukan hal yang positif mengenai Universitas XXX", dengan nilai faktor 0.577 ,

- "Universitas XXX mempunyai integritas yang baik", dengan nilai faktor 0.545 ,

- "Jika teman saya akan memilih universitas, saya akan memberitahukan teman saya untuk memilih Universitas XXX”, dengan nilai faktor terendah 0.544 .

Faktor ini dapat disebut sebagai faktor kepercayaan.

Faktor 2 yang kurang mendukung evaluasi faktor kepercayaan, getok tular, kualitas yang dipersepsi, dan kesadaran merek para siswa sekolah menengah atas di Jakarta terhadap Universitas XXX, terdiri dari faktor:

- "Universitas XXX mempunyai konsistensi hal yang positif di masyarakat", dengan nilai faktor tertinggi 0.707 ,

- "Saya percaya Universitas XXX dapat melakukan pelayanan dengan baik", dengan nilai faktor 0.703 ,

- "Program studi di Universitas XXX sesuai dengan yang saya harapkan", dengan nilai faktor 0.655 ,

- "Nama Universitas XXX sudah mencapai kondisi yang dapat dipercaya", dengan nilai faktor 0.601 ,

- "Persepsi saya mengenai kualitas Universitas XXX adalah lebih baik secara keseluruhan dibandingkan universitas lainnya yang setingkat", dengan nilai faktor 0.566 ,

- "Saya akan merekomendasikan Universitas XXX kepada teman teman saya", dengan nilai faktor terendah 0.440 .

Faktor ini dapat disebut sebagai faktor kualitas yang dipersepsi.

Faktor 3 yang sangat kurang mendukung atau tidak mendukung evaluasi faktor kepercayaan, getok tular, kualitas yang dipersepsi, dan kesadaran merek para siswa sekolah menengah atas di Jakarta terhadap Universitas XXX, terdiri dari faktor:

- "Nama Universitas XXX dijadikan salah satu hal yang layak dipelajari dalam memilih suatu universitas", dengan nilai faktor tertinggi 0.699,

- "Nama Universitas XXX sudah dikenal di Jakarta", dengan nilai faktor 0.615 ,

- "Nama Universitas XXX merupakan salah satu pilihan dalam menentukan kuliah di universitas di Jakarta", dengan nilai faktor 0.604 ,

- "Nama Universitas XXX dijadikan salah satu pertimbangan dalam memilih suatu universitas", dengan nilai faktor 0.602 ,

- "Saya percaya Universitas XXX mempunyai reputasi dan karakteristik belajar dan mengajar yang baik dan bermutu", dengan nilai faktor 0.558 ,

- "Diantara nama universitas di Jakarta, nama Universitas XXX merupakan salah satu nama yang dikenal oleh masyarakat", dengan nilai faktor 0.506 ,

- "Saya percaya Universitas XXX mempunyai style dan design mata pelajaran yang bermutu dan baik", dengan nilai faktor terendah 0.454 .

Faktor ini dapat disebut sebagai faktor kesadaran merek.

\section{Kesimpulan dan Saran}

Penulis berkesimpulan bahwa faktor yang sangat mendukung evaluasi faktor kepercayaan, getok tular, kualitas yang dipersepsi, dan kesadaran merek para siswa sekolah menengah atas di Jakarta terhadap Universitas XXX yang paling utama adalah faktor

- "Nama Universitas XXX dapat dipercaya", dengan nilai faktor tertinggi 0.706 , 
- "Universitas XXX memiliki skill dan kemampuan sesuai dengan yang diharapkan", dengan nilai faktor 0.667 ,

- "Universitas XXX mempunyai nama yang baik dan benar", dengan nilai faktor 0.635 ,

- "Universitas XXX akan berusaha untuk memuaskan para mahasiswanya yang bergabung", dengan nilai faktor 0.582 ,

- "Saya akan menyebarkan dan memberitahukan hal yang positif mengenai Universitas XXX", dengan nilai faktor 0.577 ,

- "Universitas XXX mempunyai integritas yang baik", dengan nilai faktor 0.545 ,

- "Jika teman saya akan memilih universitas, saya akan memberitahukan teman saya untuk memilih Universitas XXX”, dengan nilai faktor terendah 0.544 .

Faktor ini dapat disebut sebagai faktor kepercayaan (trust).

Faktor yang sangat dominan memberikan hasil evaluasi siswa sekolah menengah atas di Jakarta terhadap Universitas XXX adalah "Nama Universitas XXX dapat dipercaya", "Universitas XXX memiliki skill dan kemampuan sesuai dengan yang diharapkan", "Universitas XXX mempunyai nama yang baik dan benar".

Saran dari penulis adalah agar Universitas XXX tetap harus mempertahankan komunikasi dengan mengedepankan brand image yang positif yang sudah terbentuk. Disarankan agar Universitas XXX dapat mempertahankan faktor kepercayaan (trust), sehingga nama Universitas XXX yang sudah dipercaya dapat terus dipertahankan. Selain itu disarankan pula agar Universitas XXX dapat tetap memberikan bea siswa dan pada saat memperkenalkan Universitas XXX kepada siswa sekolah menengah atas agar memberitahukan fasilitas yang ada di Universitas XXX seperti galeri investasi Universitas XXX, program studi school of marketing, fasilitas praktek program studi pariwisata dan perhotelan, laboratorium bahasa, laboratorium ritel, laboratorium teknik industri, perpustakaan, dan fasilitas lainnya yang bagus dengan cara dan citra yang positif, dengan maksud agar citra merek yang sudah terbentuk dapat tetap dipertahankan citranya sebagai citra merek yang positif.

\section{Keterbatasan penelitian}

Berdasarkan pertimbangan bahwa siswa yang tinggal di Jakarta Selatan jaraknya sangat jauh untuk melakukan kuliah di Universitas XXX, maka penulis tidak menyebarkan kuesioner ke sekolah menengah atas yang berada di lokasi Jakarta Selatan

\section{Agenda penelitian mendatang}

Disarankan agar agenda penelitian mendatang dapat mengikutsertakan tambahan peubah, yaitu peubah loyalitas merek (brand loyalty), asosiasi merek (brand association) dan aset merek (brand assets) misalnya trademarks karena bagaimanapun juga menurut Aaker (2007:679-680), ekuitas merek ini dapat dibagi menjadi lima kategori, yaitu brand awareness, brand loyalty, perceived quality, brand association yang merupakan tambahan dari perceived quality, dan other brand assets, seperti patents, trademarks, channel relationships, dan lainlain.

Selain itu untuk penelitian mendatang dapat diambil sampel dari siswa sekolah menengah atas yang berada di luar Jakarta atau di luar pulau karena mahasiswa Universitas XXX tidak berasal dari siswa sekolah menengah atas yang ada di Jakarta saja, dengan maksud untuk mendapatkan hasil penelitian yang lebih baik.

\section{Daftar Pustaka}

Aaker, Kumar, Day. 2007. Maketing Research. Edisi 9, John Wiley \& Sons, Inc. New York.

Erdem, T., Swait, J. 2004. Brand Credibility, Brand Consideration, and Choice. Journal of Consumer Research, 31(1), 191-198. 
Hair, Black, Babin, Anderson, 2010. Multivariate Data Analysis. Edisi 7, Pearson Education, Inc. Upper Saddle River, New Jersey.

Keller, K.L. 2013. Strategic Brand Management: Building, Measuring, and Managing Brand Equity. Edisi 4, Pearson Education, Inc., USA.

Malhotra, N.K. 2010. Marketing Research, An Applied Orientation. Edisi 6, Pearson Education, Inc. Upper Saddle River, New Jersey.

Maxham, J.G. I.I.I., Netemeyer, R.G. 2003. Firms reap what they sow: The effects of shared values and perceived organizational justice on customers' evaluations of complaint handling. Journal of Marketing, 67(1), 46-62.

Nisfiannoor, M. 2009. Pendekatan Statistika Modern untuk Ilmu Sosial. Penerbit Salemba Humanika. Jakarta.

Sumaedi, Bakti, Y., Rakhmawati, J., Widianti, A.T., Yarmen, M. 26 July, 2014. Journal The Empirical Study on Patient Loyalty, The Role of Trust, Perceived Value and Satisfaction (a case study from Bekasi Indonesia), Indonesian Institute of Science, Tangerang Selatan, Indonesia.

Umar, H. 2003. Metode Riset Bisnis. Edisi 2, PT Gramedia Pustaka Utama. Jakarta.

Uyanto, S.S. 2009. Pedoman Analisis Data dengan SPSS. Edisi 3, Penerbit Graha Ilmu. Yogyakarta. 